\title{
Zastosowanie leków anty-VEGF w leczeniu retinopatii wcześniaków
}

\author{
Anti-VEGF drugs in treatment of retinopathy of prematurity
}

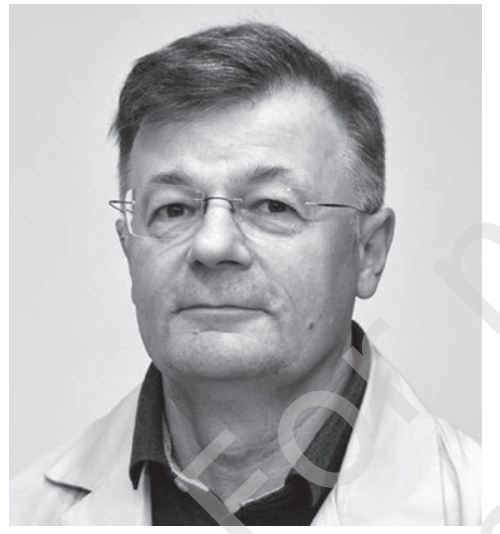

N A JW A ŻN IE JSZE

Leki VEGF w terapii retinopatii wcześniaków należy stosować bardzo rozważnie, tylko u pacjentów z retinopatią w I strefie. Złotym standardem jest wciąż laserowa fotokoagulacja.

H I G H L I G H TS VEGF drugs in the treatment of retinopathy of prematurity should be used very carefully, only in patients with retinopathy in zone I. Laser photocoagulation still remains the gold standard.

\begin{abstract}
STRESZCZENIE
Retinopatia wcześniaków jest poważnym schorzeniem siatkówki, mogącym doprowadzić do jej odwarstwienia i w konsekwencji do utraty widzenia. W patogenezie tej choroby kluczową rolę odgrywają wytwarzane w nadmiarze naczyniowo-śródbłonkowe czynniki wzrostu (VEGF, vascular endothelial growth factors). Złotym standardem leczenia jest wciąż stosowana od lat 90. XX w. laserowa fotokoagulacja obwodowej nieunaczynionej siatkówki. Wprowadzone w ostatnich latach leki anty-VEGF podawane w postaci iniekcji do ciała szklistego neutralizują wytworzone w nadmiarze czynniki VEGF. Podstawowymi zaletami tych leków są: bardzo szybkie działanie, bardzo krótka i nieskomplikowana procedura podania oraz spodziewane pełne pole widzenia. Leki są jednak wchłaniane do krwiobiegu, co może zaburzać fizjologiczne dojrzewanie narządów wewnętrznych u dziecka urodzonego przedwcześnie. Innym ważnym problemem jest pojawienie się późnych wznów retinopatii, nawet kilka miesięcy po iniekcji. Leki te powinny być stosowane rozważnie, przede wszystkim u pacjentów z retinopatią w I strefie.
\end{abstract}

Słowa kluczowe: retinopatia wcześniaków, leki anty-VEGF, fotokoagulacja laserowa siatkówki

\section{ABSTRACT}

Retinopathy of prematurity is a serious disease that can lead to retinal detachment and vision loss. Vascular endothelial growth factors (VEGF) play a key role in the pathogenesis of this disease. The gold standard of treatment used since the 1990s is laser coagulation of non-vascularized retina. Anti-VEGF drugs introduced in recent years administered as intravitreal injections neutralize excess VEGF factors. The main advantage of these drugs is very fast action, very short and uncomplicated administration procedure, full field of view expected. Drugs, however, are absorbed into the bloodstream, which can affect the physiological maturation of internal organs in a child born prematurely. Another important problem is the appearance of late recurrences of retinopathy, even several months after the injection. These drugs should be used prudently, especially in patients with retinopathy in zone I.

Key words: retinopathy of prematurity, anty-VEGF drugs, laser photocoagulation of the retina 


\section{WSTĘP}

Retinopatia wcześniaków (ROP, retinopathy of prematurity) jest proliferacyjnym schorzeniem siatkówki i ciała szklistego, którego przyczyną są zaburzenia w procesie fizjologicznego unaczynienia siatkówki stwierdzane u dzieci urodzonych przedwcześnie. Zaburzenia te mogą prowadzić do patologicznego rozrostu naczyń i tkanki włóknistej w obrębie ciała szklistego, następnie do pociągania i odwarstwienia siatkówki, a w konsekwencji do utraty widzenia. Nowoczesne metody leczenia schorzenia są skuteczne pod warunkiem zastosowania ich w ściśle określonym czasie. Do metod tych należą koagulacja obwodowej, nieunaczynionej siatkówki (laserowa fotokoagulacja i wcześniej stosowana krioterapia) oraz wprowadzone w ostatnich latach iniekcje do ciała szklistego leków anty-VEGF. Celem pracy jest przedstawienie zalet $i$ wad najnowszej metody leczenia retinopatii wcześniaków - zastosowania leków anty-VEGF.

\section{PATOGENEZA I OBRAZ KLINICZNY RETINOPATII WCZEŚNIAKÓW}

Do 4. miesiąca życia płodowego siatkówka pozbawiona jest naczyń. Od tego czasu od tarczy nerwu wzrokowego w kierunku obwodu zaczynają wnikać komórki mezenchymy, które tworzą pierwotne „sznury” ulegające kanalizacji (pierwotne naczynia). Na granicy strefy unaczynionej i nieunaczynionej rozwija się pierwotna, gęsta, „wielookienkowa" waskulatura. Część tych pierwotnych naczyń ulega apoptozie, część z nich pozostaje i jest modelowana w ostateczne tętnice i żyły siatkówki. Proces ten jest regulowany głównie przez naczyniowo-śródbłonkowy czynnik wzrostu (VEGF, vascular endothelial growth factor). Wytwarzanie tego czynnika jest stymulowane przez niedotlenienie obwodowych, nieunaczynionych obszarów, w których dojrzewają komórki siatkówki. VEGF stymuluje proliferację komórek mezenchymy i rozwój unaczynienia siatkówki. $\mathrm{Na}$ obszarach już unaczynionych stężenie tlenu wzrasta, co powoduje hamowanie wytwarzania VEGF. Równowaga procesów wytwarzania i hamowania czynnika VEGF trwa w obrębie siatkówki do momentu zakończenia jej unaczynienia [1].

W ostatnich latach podkreśla się znaczenie insulinopodobnego czynnika wzrostu (IGF-1, insulin-like growth factor-1). Poziom IGF-1 w surowicy płodu systematycznie wzrasta w ciągu całej ciąży, osiągając najwyższe wartości w III trymestrze, i gwałtownie spada po urodzeniu. Uważa się, że IGF-1 jest niezbędny do prawidłowego rozwoju naczyń (aktywuje wytwarzanie VEGF). Spadek poziomu IGF-1 po przedwczesnym porodzie może powodować zatrzymanie prawidłowego unaczynienia siatkówki. Im wcześniej jest urodzone dziecko, tym większy obszar siatkówki nieunaczynionej się stwierdza i tym większe jest prawdopodobieństwo rozwoju retinopatii (ryc. 1).

W rozwoju retinopatii można wyróżnić dwie fazy: wazoobliteracyjną i wazoproliferacyjną. Faza wazoobliteracyjna rozwija się ok. 30.-32. tygodnia życia płodowego. Dochodzi wówczas do obliteracji niedojrzałych naczyń siatkówki i do zahamowania procesu jej unaczynienia. Zbyt wczesny poród zmusza do zastosowania tlenoterapii, aby nie doszło do uszkodzenia narządów wewnętrznych, szczególnie

\section{RYCINA 1}

Rozwój unaczynienia siatkówki oraz strefy retinopatii. W części nosowej proces

unaczynienia kończy się wcześniej (8. miesiąc) ze względu na anatomicznie bliższą odległośc pomiędzy tarczą nerwu wzrokowego a rąbkiem zębatym.

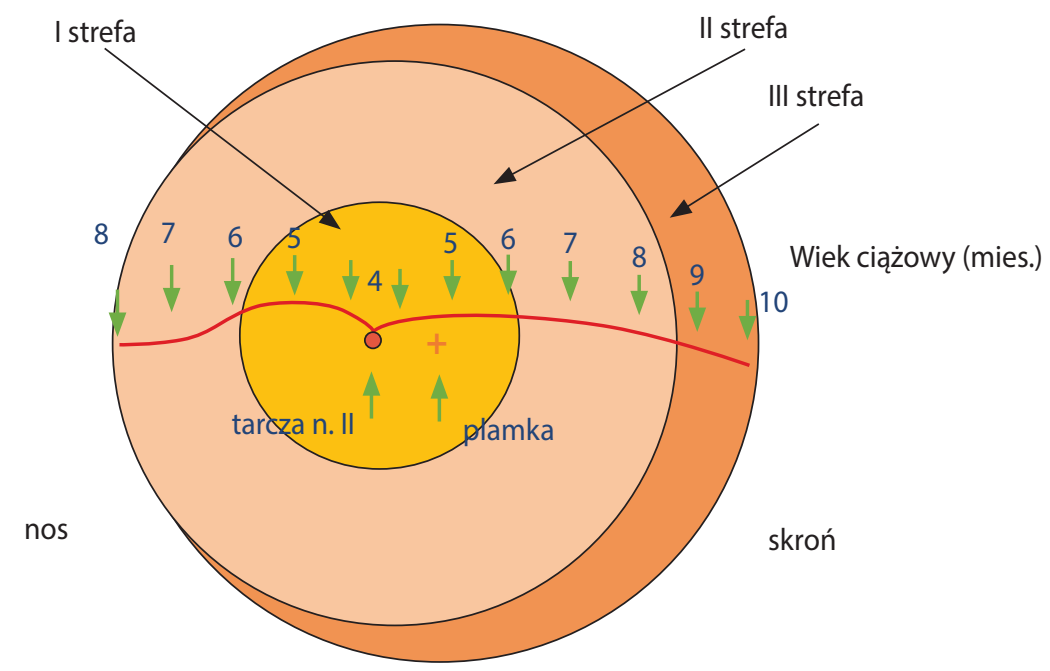


centralnego układu nerwowego. Ciśnienie parcjalne tlenu w krwi tętniczej u płodu w macicy wynosi ok. $30 \mathrm{mmHg}$ i wzrasta do 60-100 mmHg w wyniku zastosowania tlenoterapii w inkubatorze. Podwyższone stężenie tlenu we krwi tętniczej powoduje skurcz i zwężenie tętnic, a wolne rodniki tlenowe uszkadzają śródbłonek niedojrzałych naczyń. Dodatkową istotną rolę w tym procesie odgrywają niedojrzałe układy antyoksydacyjne występujące u najbardziej niedojrzałych wcześniaków. Hiperoksja prowadzi również do zahamowania wytwarzania w pobliżu niedojrzałych naczyń naczyniowo-śródbłonkowego czynnika wzrostu, który zapobiega apoptozie komórek śródbłonka, w następstwie zapobiega obliteracji naczyń. Procesy te skutkują zatrzymaniem procesu unaczynienia siatkówki - zahamowaniem wnikania dojrzewających naczyń w kierunku obwodu.

Pojawia się linia demarkacyjna - 1. stadium retinopatii wcześniaków. Naczyniotwórcza tkanka mezenchymalna przestaje wnikać do jej obwodowych, nieunaczynionych części i gromadzi się w postaci tzw. mezenchymalnego krążenia obocznego, które klinicznie odpowiada wałowi - 2. stadium retinopatii. Zarówno stadium 1., jak i 2. mają tendencję do samoistnej regresji. Nasilająca się jednak hipoksja na obszarze nieunaczynionym stymuluje wytwarzanie dużej ilości VEGF i może prowadzić do rozwoju fazy wazoproliferacyjnej - zwykle ok. 32.-34. tygodnia życia płodowego. Na skutek wytwarzania w nadmiarze czynnika VEGF przez niedotlenioną, nieunaczynioną, obwodową część siatkówki dochodzi do nadmiernego rozwoju naczyń, a następnie tkanki włóknistej [2]. Pojawia się 3. stadium retinopatii - proliferacje naczyniowo-włókniste, które najpierw rozwijają się na wale, a następnie zaczynają wnikać do ciała szklistego. Ponieważ do części obwodowej, nieunaczynionej, nie wnikają naczynia krwionośne, w obszarze tym na skutek trwającej hipoksji stale wytwarzany jest w nadmiarze czynnik VEGF, który pobudza dalszy rozwój proliferacji naczyniowo-włóknistych. Towarzysząca proliferacjom tkanka włóknista ma tendencję do obkurczania się, co może skutkować pociąganiem i częściowym (4. stadium) lub całkowitym (5. stadium retinopatii) odwarstwianiem dojrzałej, unaczynionej już siatkówki. U dzieci najbardziej niedojrzałych stwierdza się tzw. postać tylną agresywną retinopatii. W tych przypadkach schorzenie występuje w I strefie, obserwuje się kręte i szerokie naczynia siatkówki (objaw „plus”), a retinopatia ma piorunujący przebieg (ryc. 2.)

Trzeba podkreślić, że dokładny mechanizm rozwoju retinopatii wciąż nie jest do końca jasny. W ostatnich latach podkreśla się znaczenie czynników genetycznych. Potwierdzić to mogą obserwacje lekarzy zajmujących się diagnostyką i leczeniem retinopatii wcześniaków. Obserwują oni paradoksalne występowanie szybko postępującej retinopatii u dzieci ze stosunkowo późnym wiekiem ciążowym oraz dość dużą masą urodzeniową i odwrotnie - niektóre

\section{RYCINA 2}

Postać tylna agresywna retinopatii. Zmiany występują

w I strefie, obecny objaw „plus", pacjent wymaga bardzo pilnej interwencji ze względu na piorunujący przebieg schorzenia.

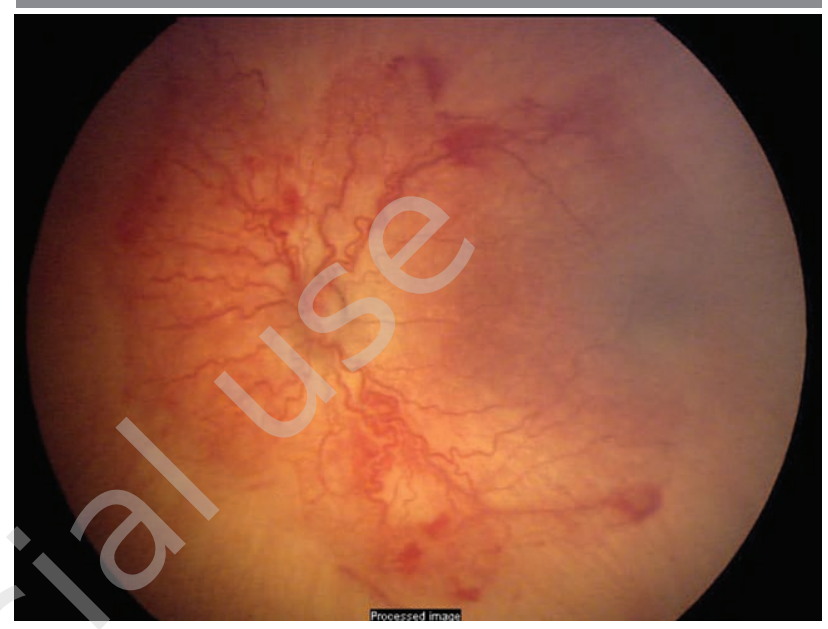

skrajnie niedojrzałe dzieci retinopatii nie rozwijają. Dzieje się tak pomimo stosowania identycznych procedur opieki neonatologicznej w pierwszym, kluczowym dla rozwoju retinopatii, okresie życia.

\section{LECZENIE RETINOPATII WCZEŚNIAKÓW}

Celem leczenia fazy czynnej jest niedopuszczenie do rozwoju proliferacji naczyniowo-włóknistych i pociągania, a w konsekwencji - do odwarstwienia siatkówki. Zatrzymanie rozwoju proliferacji można osiągnąć przy użyciu dwóch metod: koagulacji obwodowego, nieunaczynionego obszaru siatkówki (skutkującej zniszczeniem znajdujących się tam elementów komórkowych i zatrzymaniem wytwarzania w nadmiarze czynnika VEGF) lub podania do ciała szklistego leków neutralizujących już wytworzone czynniki VEGF [3, 4]. Na podstawie wieloośrodkowego badania klinicznego ET-ROP (Early Treatment for Retinopathy of Prematurity) wyodrębniono dwa typy retinopatii: typ 1 rozpoznawany jest wówczas, gdy choroba występuje w strefie I - każde stadium z towarzyszącą chorobą "plus” lub stadium 3. bez choroby „plus” lub gdy w strefie II stwierdza się stadium 2. lub 3. z chorobą „plus”; typ 2 jest rozpoznawany, gdy w strefie I występuje stadium 1 . lub 2. bez choroby "plus” lub gdy w strefie II stwierdza się stadium 3 . bez choroby „plus”. Typ 1 wymaga leczenia, w typie 2 zaleca się obserwację [5].

\section{Koagulacja pierwotnie nieunaczynionej siatkówki}

Pierwszą skuteczną metodą leczenia retinopatii była krioterapia wprowadzona w latach 70. XX w. przez japońskich okulistów. Krioterapię wykonywano przeztwardówkowo, pod kontrolą wzroku, przy użyciu wziernika pośredniego. 
Pod koniec lat 80. ubiegłego wieku krioterapię zaczęto zastępować fotokoagulacją laserową. Stało się to dzięki wprowadzeniu przenośnych laserów, które zostały sprzężone z wziernikiem pośrednim.

Zasada wykonania obu zabiegów polega na zniszczeniu za pomocą niskiej temperatury (krioterapia) lub energii laserowej (fotokoagulacja) obwodowej nieunaczynionej siatkówki. Koagulacja jest zabiegiem skutecznym pod warunkiem pokrycia całego obszaru nieunaczynionego, od wału z proliferacjami aż do rąbka zębatego. Dobry efekt leczenia można uzyskać poprzez wykonanie zabiegu tylko w ściśle określonym czasie - gdy proliferacje naczyniowe nie są duże. Brak pełnej koagulacji, z pozostawieniem obszarów nieunaczynionych, skutkuje progresją retinopatii i w konsekwencji może prowadzić do odwarstwienia siatkówki. Ze względu na większą precyzję zabiegu, a co za tym idzie - lepsze efekty anatomiczne oraz czynnościowe fotokoagulacja laserowa wyparła krioterapię. Różnice w skuteczności leczenia są widoczne szczególnie u pacjentów bardziej niedojrzałych, z retinopatią w I strefie (tab. 1). Zabieg laserowy jest trudny pod względem technicznym - znacznie trudniejszy od krioterapii, czasochłonny (konieczność wykonania nawet kilku tysięcy ognisk) i wymaga dużego doświadczenia (ryc. 3). Po fotokoagulacji laserowej stwierdza się również rzadsze efekty uboczne (tab. 2). W związku z powyższym fotokoagulacja laserowa siatkówki stała się złotym standardem w leczeniu retinopatii wcześniaków.

\section{RYCINA 3}

Retinopatia 3. stopnia w II strefie bezpośrednio po zabiegu fotokoagulacji. Cały obszar pierwotnie nieunaczynionej siatkówki skoagulowany.

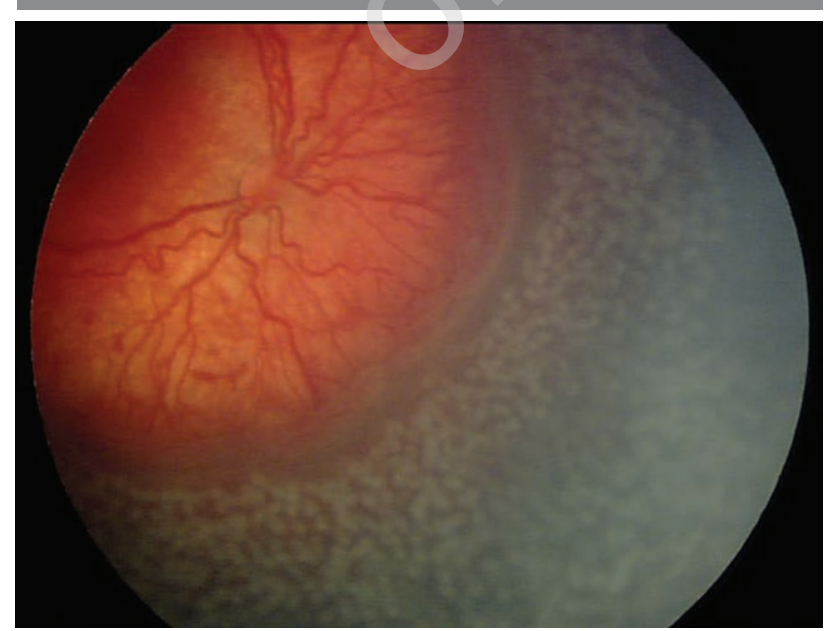

TABELA 1

Efekty leczenia przy użyciu fotokoagulacji laserowej i krioterapii. Jako dobry efekt leczenia uznano według kryteriów wieloośrodkowych badań CRYO-ROP Study: brak anatomicznych zmian w plamce lub ektopię plamki; jako zły efekt leczenia: fałd siatkówki, częściowe i całkowite odwarstwienie siatkówki.

\begin{tabular}{c|c|c}
$\begin{array}{c}\text { Dobry wynik } \\
\text { leczenia }\end{array}$ & $\begin{array}{c}\text { Laserowa } \\
\text { fotokoagulacja* } \\
\text { \% leczonych oczu }\end{array}$ & $\begin{array}{c}\text { Krioterapia** } \\
\text { \% leczonych oczu }\end{array}$ \\
\hline Retinopatia w I strefie & 79,6 & 22,2 \\
\hline Retinopatia w II strefie & 89,1 & 73,9
\end{tabular}

* Na podstawie [6] (analiza 267 pacjentów)

** Na podstawie [7] (analiza 273 pacjentów).

\section{TABELA 2}

Powikłania po laserowej fotokoagulacji i krioterapii.

\begin{tabular}{c|c|c} 
Powikłanie & Laser* (\%) & $\begin{array}{c}\text { Krioterapia** } \\
\text { (\%) }\end{array}$ \\
\hline Krwotoki przedsiatkówkowe & 3,6 & 22,3 \\
\hline $\begin{array}{c}\text { Przegrupowanie barwnika } \\
\text { w plamce }\end{array}$ & 0,5 & 14,7 \\
\hline Zapalenie błony naczyniowej & 0,8 & 6,3 \\
\hline Wysięki siatkówkowe & - & 4,7 \\
\hline Stałe przekrwienie spojówki (blizny) & - & 4,5 \\
\hline Otwory siatkówki & - & 3,1 \\
\hline Hipotonia gałki ocznej & - & 1,8 \\
\hline Masywne krwotoki do ciała & - & 1,4 \\
\hline szklistego & - & 1,3 \\
\hline Zmętnienie rogówki & - & 1,3 \\
\hline Zanik tęczówki & - & 1,1 \\
\hline Zanik nerwu wzrokowego & - & 0,5 \\
\hline Otwór w plamce & 0,4 & 0,4 \\
\hline Jaskra & 0,3 & -
\end{tabular}

* Na podstawie [6] (analiza 267 pacjentów).

** Na podstawie [7] (analiza 273 pacjentów).

Podstawowym ograniczeniem wykonywania zabiegów koagulacyjnych jest brak wglądu w dno oka. Problem ten może występować u wcześniaków najbardziej niedojrzałych (zmętniałe ciało szkliste, mniej przezierna rogówka, obecność w obrębie źrenicy błony tunica vasculosa lentis) oraz u dzieci z zaćmą. Mniej przezierne ośrodki optyczne oka praktycznie uniemożliwiają wykonanie fotokoagulacji laserowej, choć krioterapia jest wciąż możliwa. Aby zastosować krioterapię u pacjentów $\mathrm{z}$ retinopatią w I strefie, trzeba wykonać chirurgiczne otwarcie spojówki (tzw. otwarta krioterapia), ponieważ jej fizjologiczne załamki są zbyt płytkie do zamrożenia całego obszaru nieunaczynionego. Krioterapia w takich przypadkach daje wiele powikłań. Generalnie u pacjentów najbardziej niedojrzałych, z retinopatią w I strefie istnieje konieczność wykonania bardzo rozległej koagulacji 
siatkówki, co skutkuje znacznym zwężeniem pola widzenia, zwiększa ryzyko powikłań oraz niepowodzenia leczenia. Trzeba również pamiętać o odległych efektach rozległej koagulacji siatkówki u dzieci urodzonych przedwcześnie: niezborności i krótkowzroczności. Stwierdzane wady są szczególnie wysokie u pacjentów po krioterapii.

\section{Zastosowanie leków anty-VEGF}

Na początku XXI w. wprowadzono leki (przeciwciała monoklonalne), które podane do ciała szklistego łączą się z wytworzonymi czynnikami VEGF, co powoduje ich dezaktywację. Leczenie jest proste, szybkie, a efekty natychmiastowe. Natychmiastowy efekt - widziany już kolejnego dnia po iniekcji - występuje dzięki błyskawicznemu blokowaniu już wytworzonych czynników wzrostu VEGF. Inaczej jest po zabiegach koagulacyjnych, które hamują wytwarzanie nowych czynników wzrostu, ale te już wytworzone są aktywne przez kilka dni, co jest widoczne u niektórych pacjentów $\mathrm{w}$ postaci progresji retinopatii w pierwszych dniach po zabiegu. Dlatego iniekcje leków anty-VEGF powinny być stosowane przede wszystkim u pacjentów z retinopatią w I strefie, szczególnie gdy występuje postać tylna agresywna (ryc. 4).

Krótki czas zabiegu zwiększa bezpieczeństwo znieczulenia ogólnego, co jest istotne u ekstremalnie niedojrzałych dzieci ze wspólistniejącą niewydolnością oddechową. Dużą zaletą leczenia retinopatii lekami anty-VEGF w porównaniu z zabiegami koagulacyjnymi jest brak wyłączenia obwodu siatkówki, a w konsekwencji pełne pole widzenia. Do wykonania iniekcji nie są konieczne przezierne ośrodki optyczne. Podstawową wadą tych leków jest częściowe przedostawanie się do krwi obwodowej i blokowanie endogennych czynników VEGF, niezbędnych do prawidłowego rozwoju wielu narządów [8]. Przeprowadzone badania wskazują powrót do fizjologicznego stężenia endogennych VEGF w surowicy po podaniu ranibizumabu po 2-3 tygodniach, a po podaniu bewacyzumabu aż po 2 miesiącach $[9,10]$ ! Może to powodować zaburzenie rozwoju różnych narządów, $\mathrm{w}$ tym centralnego układu nerwowego (CUN). Dlatego leki anty-VEGF powinny być stosowane bardzo rozważnie, przede wszystkim u wcześniaków, u których stwierdza się retinopatię w I strefie z chorobą „plus” lub u których pomimo wykonania fotokoagulacji laserowej obserwuje się progresję choroby.

Innym wskazaniem jest zły stan ogólny pacjenta i brak możliwości zastosowania długiego znieczulenia ogólnego, które jest niezbędne do prawidłowo wykonanej fotokoagulacji laserowej [11]. Dodatkowym problemem obserwowanym po zastosowaniu leków anty-VEGF jest możliwość pojawienia się wznowy schorzenia, nawet po wielu miesiącach od iniekcji. Według niektórych autorów ryzyko wznowy po iniekcji może wynosić aż 50\% [12]! Wznowy nie są obserwowane u dzieci, u których prawidłowo wykonano (skoagulowany

\section{RYCINA}

Retinopatia wcześniaków. A. Stan przed leczeniem, zmiany

w I strefie, obecny objaw "plus". B. 7 dni po podaniu ranibizumabu, regresja choroby.

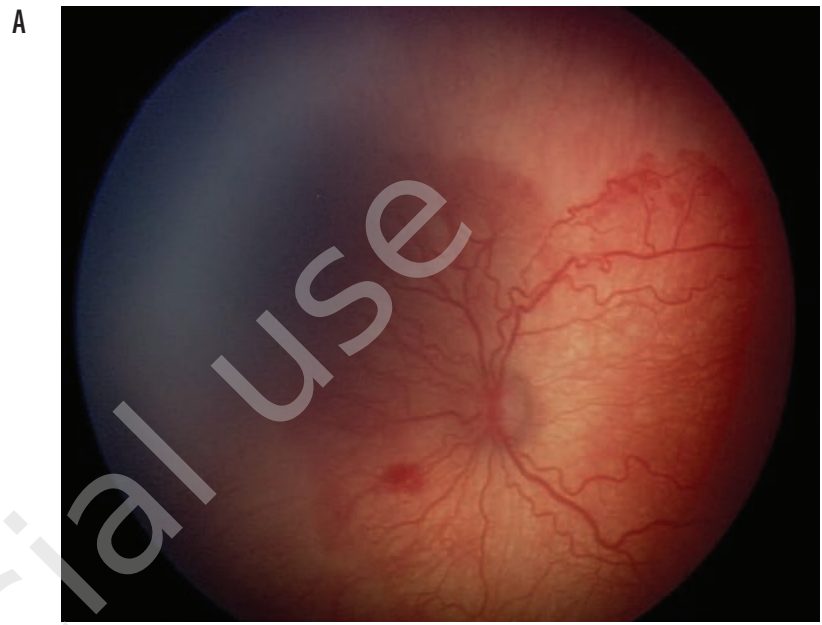

B

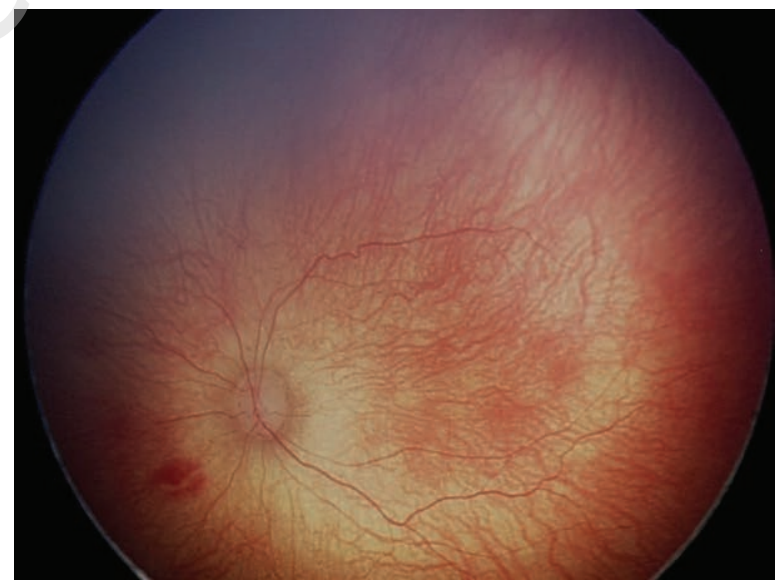

cały nieunaczyniony obszar siatkówki) fotokoagulację. Najskuteczniejszą metodą leczenia późnej wznowy po leczeniu anty-VEGF jest fotokoagulacja laserowa obwodowej, nieunaczynionej siatkówki. Ze względu na możliwość wystąpienia późnej wznowy u dzieci, które były leczone iniekcjami anty-VEGF i u których stwierdza się obwodowe obszary nieunaczynione, muszą być kontrolowane bardzo długo. Badanie obwodu siatkówki u kilku-kilkunastomiesięcznych dzieci jest trudne i w wielu przypadkach do potwierdzenia pojawienia się wznowy niezbędne jest wykonanie angiografii fluorescencyjnej. Angiografia $u$ takich małych, niewspółpracujących dzieci może być wykonana tylko w znieczuleniu ogólnym w pozycji leżącej, co wymaga zastosowania drogiej aparatury (RETCAM). Porównanie zalet i wad fotokoagulacji laserowej i iniekcji leków anty-VEGF przedstawiono w tabeli 3. 


\begin{tabular}{c|c|c}
\multicolumn{2}{c}{ Porównanie metod leczenia retinopatii wcześniaków. } \\
\hline Kosztowny sprzęt medyczny & Fotokoagulacja laserowa & Iniekcje leków anty-VEGF \\
\hline Czas zabiegu & konieczny & niekonieczny \\
\hline Technika zabiegu & długi & bardzo krótki \\
\hline Przezierne ośrodki optyczne & trudna & łatwa \\
\hline Reakcja na leczenie & konieczne & natychmiastowa \\
\hline Najpoważniejsze powikłanie miejscowe & po 2-3 dniach \\
\hline Ryzyko powikłán ogólnych & zráma & możliwe \\
\hline Ryzyko wznowy & małe & wysokie \\
\hline Późna wznowa & brak & możliwa \\
\hline Wady refrakcji indukowane leczeniem & wysokie & brak \\
\hline Pole widzenia & zwężone & prawidłowe
\end{tabular}

Iniekcje do ciała szklistego podaje się standardowo przez pars plana. Należy jednak pamiętać o innych warunkach anatomicznych oka dziecka urodzonego przedwcześnie: miejsce wkłucia powinno być oddalone od rąbka o 2-2,5 mm, a kierunek wbijania igły bardziej pionowy w stronę tylnego bieguna oka - ze względu na możliwość uszkodzenia bardziej kulistej soczewki. Najpoważniejszym powikłaniem iniekcji doszklistkowej jest zapalenie wnętrza gałki ocznej, dlatego zabiegi te powinny być przeprowadzane z zachowaniem wszelkich zasad aseptyki, tak jak operacje wewnątrzgałkowe. Na rynku są obecnie dostępne trzy preparaty anty-VEGF: bewacyzumab (Genetech/Roche), ranibizumab (Novartis) i aflibercept (Bayer). Pierwszy do terapii został wprowadzony bewacyzumab. Jest to lek niezarejestrowany do leczenia schorzeń gałki ocznej. Jednak dzięki dobrym efektom jego stosowania oraz niskiej cenie stał się popularny w leczeniu różnych schorzeń naczyniowych siatkówki, a także retinopatii wcześniaków, szczególnie w USA. Ranibizumab i aflibercept są lekami zarejestrowanymi do stosowania w okulistyce, jednak tylko ranibizumab od 2019 r. jest zarejestrowany we wskazaniu „retinopatia wcześniaków”. Pozostałe preparaty są stosowane poza wskazaniami i wymagają zgody odpowiedniej dla danej kliniki komisji bioetycznej oraz podpisania rozbudowanej świadomej zgody opiekunów prawnych wcześniaka. Bewacyzumab ma najdłuższą cząsteczkę i utrzymuje się w tkankach oka najdłużej. Działa więc długo i rzadziej ob- serwuje się późne wznowy. Z drugiej strony bardzo długo blokuje endogenny VEGF, co może indukować powikłania ogólne. Pomimo krótszego działania w oku pozostałe leki, ze względu na mniejsze ryzyko powikłań ogólnych, powinny być stosowane w leczeniu retinopatii wcześniaków z wyboru.

\section{PODSUMOWANIE}

Wprowadzenie leków anty-VEGF poprawiło skuteczność leczenia retinopatii wcześniaków. Złotym standardem wciąż jednak pozostaje fotokoagulacja laserowa. W ostatnich latach, dzięki doskonaleniu opieki neonatologicznej, obraz retinopatii wcześniaków w Polsce uległ zmianie. Coraz większą liczbę dzieci z ekstremalnie niską urodzeniową masą ciała i wczesnym wiekiem ciążowym udaje się zachować przy życiu. Generalnie retinopatię wymagającą leczenia stwierdza się coraz rzadziej, lecz gdy już się ona rozwija, dotyczy dzieci bardzo niedojrzałych, a schorzenie występuje w I strefie. Iniekcje leków anty-VEGF są najbardziej skuteczne w takich przypadkach. Należy się więc spodziewać coraz powszechniejszego ich stosowania w leczeniu retinopatii wcześniaków.

Źródło rycin: Wszystkie ryciny pochodza z materiałów własnych autora/autorów.

ORCID

Wojciech Hautz - ID - http://orcid.org/0000-0003-2065-8646
ADRES DO KORESPONDENCJ

dr hab. n. med. Wojciech Hautz

Klinika Okulistyki,

Instytut "Pomnik - Centrum Zdrowia Dziecka”

04-730 Warszawa, al. Dzieci Polskich 20

e-mail:W.Hautz@IPCZD.PL 


\section{Piśmiennictwo}

1. Smith LE. Pathogenesis of retinoparthy of prematurity. Acta Pediatr. 2002; suppl 437: 26-8.

2. Hellstrom A, Smith LE, Dammann O. Retinopathy of prematurity. Lancet. 2013; 382(9902): 1445-57.

3. Hansen ED, Hartnett ME. A review of treatment for retinopathy of prematurity. Expert Rev Ophthalmol. 2019; 14(2): $73-87$.

4. Hartnett EM. VEGF antagonist therapy for ROP. Clin Perinatol. 2014; 41(4): 925-43.

5. Early Treatment for Retinopathy of Prematurity Cooperative Group. Revised indications for treatment of retinopathy of prematurity: results of the early treatment for retinopathy of prematurity randomized trial. Arch Ophthalmol. 2003; 121: 1684-94.

6. Hautz W. Ocena wyników leczenia retinopatii wcześniaków przy użyciu laserowej fotokoagulacji. Praca doktorska. Instytut „Pomnik - Centrum Zdrowia Dziecka", Warszawa 2004.

7. Multicenter Trial of Cryotherapy for Retinopathy of Prematurity. Three-month Outcome. Cryotherapy for Retinopathy of Prematurity Cooperative Group. Arch Ophthalmol. 1990; 108(2): 195-204.

8. Arima M, Akiyama M, Fujiwara $\mathrm{K}$ et al. Neurodevelopmental outcomes following intravitreal bevacizumab injection in Japanese preterm infants with type 1 retinopathy of prematurity. PLoS ONE. 15(3): e0230678.

9. Wong RK, Hubschman S, Tsui I. Reactivation of Retinopathy of Prematurity after Ranibizumab Treatment. Retina. 2015; 35(4): 675-80.

10. Stahl A, Hellstrom A, Smith LE. IGF-1 and Anti-VEGF in ROP: Has the time come? Neonatology. 2014; 106(3): 254-60.

11. VanderVeen DK, Meila M, Yang MB et al. Anti-vascular endothelial growth factor therapy for primary treatment of type 1 retinopathy of prematurity. Ophthalmology. 2017; 124: 619-33.

12. Zang $G$, Yang $M$, Zeng J et al. Comparsion of intravitreal injection of ranibizumab versus laser theapy for zone II treatment - requiring retinopatopathy of prematurity. Retina. 2017; 37: 710-7.

\section{Konflikt interesów:}

Nie wystęuje.

Finansowanie:

Nie występuje.

Etyka:

Treści przedstawione w artykule są zgodne z zasadami Deklaracii Helsińskiej, dyrektywami EU oraz ujednoliconymi wymaganiami dla czasopism biomedycznych.
Conflict of interest:

None.

Financial support:

None.

Ethics:

The content presented in the article complies with the principles of the Helsinki Declaration, EU directives and harmonized requirements for biomedical journals. 